\title{
The Predictive Value of Germline Polymorphisms in Patients with NSCLC
}

\author{
Anneli D. Nygaard ${ }^{1}$, Karen-Lise G. Spindler ${ }^{1}$, Christa H. Nyhus ${ }^{1}$, Rikke F. Andersen ${ }^{2}$, \\ Anders Jakobsen ${ }^{1}$ \\ ${ }^{1}$ Department of Oncology, Vejle Hospital, Vejle, Denmark; ${ }^{2}$ Department of Biochemistry, Vejle Hospital, Vejle, Denmark. \\ Email: anneli.nygaard@slb.regionsyddanmark.dk
}

Received September $17^{\text {th }}, 2010$; revised October $15^{\text {th }}, 2010$; accepted November $5^{\text {th }}, 2010$.

\begin{abstract}
Lung cancer is one of the most common cancers in the western world, and closely related to smoking. The majority of the patients can not be offered treatment with curative intent. Palliative chemotherapy has limited effect but a considerable level of toxicity. Predictive markers are therefore urgently needed. Single Nucleotide Polymorphisms (SNPs) are stable markers of potential clinical value and the study aimed at evaluating their use in lung cancer patients given standard chemotherapy. Genomic DNA was extracted from a pre-treatment blood sample drawn from patients with advanced Non-Small Celled Lung Cancer (NSCLC), referred to palliative chemotherapy (Carboplatin and Vinorelbine) at the Department of Oncology, Vejle Hospital, between 2007 and 2010. Eighty-seven patients were included in a test cohort, and 161 patients in an independent validation cohort. A panel of $10^{7}$ SNPs in the EGF, VEGF and $D N A$-excision repair systems was investigated. The primary endpoint was response rates (RR). Secondary endpoints were progression free survival (PFS) and overall survival (OS). SNPs with significant association to outcome in the test cohort were further tested in the validation cohort. Haplotypes were estimated and analyzed when relevant. There were no significant associations between SNPs in the EGF system or the DNA-repair system and RR, PFS or OS. In contrast, the VEGF+405, VEGF-460 and VEGF-2579, heterozygous patients had a higher response rate and longer PFS than homozygous patients. Haplotype analysis of the VEGF+405 and VEGF-460 supported our findings. These results were, however, not confirmed in the validation cohort. Although significant results regarding VEGF related SNPs, in the primary analysis, no predictive value of a broad panel of SNPs in NSCLC was found in the validation cohort, underlining the importance of independent validation of biomarker analysis.
\end{abstract}

Keywords: NSCLC, EGF, VEGF, DNA excision repair, SNPS

\section{Introduction}

Lung cancer is one of the most common malignant disorders in the western world with a clear association to smoking [1]. About $80 \%$ of the tumors are classified as non-small-celled lung cancer (NSCLC). The disease has considerable morbidity and mortality with a five years survival of less than 10 percent. Radical treatment by surgery or radiotherapy is possible in a minority of the cases, but most patients are diagnosed in an advanced stage, with no curative treatment option available. These patients will normally be offered palliative chemotherapy, and/or radiotherapy. A combination of platinum based chemotherapy (Carboplatin or Cisplatin) and Vinorelbine remains a cornerstone in first-line treatment of NSCLC. The response rate, however, is low (around $30 \%$ ) [1-3] and the treatment is associated with considerable toxicity $[4,5]$.

The traditional way of selecting patients for chemotherapy is based on different patient characteristics such as histopathology, age and performance status (PS). However, these characteristics are unspecific and contain little information with respect to selection of responsive patients. Also, new treatments are emerging at a high rate, urging the need for more specific markers to enable a higher degree of individualized treatments.

Single Nucleotide Polymorphisms (SNPs) are germline alterations, and hence present in all cells of the body. The human gene contains approximately $10^{7}$ SNPs and the great majority seems to be of little or no biological importance. Some few, however, are functional and affecting the corresponding proteins, e.g. MTHFR [6]. SNPs in genes affecting pharmacokinetics and or phar- 
macodynamics of drugs may influence the response to therapy and consequently serve as predictive markers. Some SNPs can be arranged in to haplotypes, depending on how closely related they are on the gene. This is illustrated by the linkage disequilibrium (LD), which describes the level of correlation between the alleles, the higher correlation, the higher LD. The combination of SNPs into haplotypes thus provides a way of investigating the combined effect of several SNPs. The SNPs have gained increasing interest in recent years along with the deeper knowledge of different growth regulating systems serving as targets for new therapy. In the present study, three different biological systems known to be important to tumor growth and treatment response were investigated. The EGF and VEGF-systems play a prominent role in this aspect. Also the DNA excision repair system is of major interest.

The Epidermal Growth Factor (EGF) system is involved in growth regulation and it also plays a major role in carcinogenesis and tumor spread [7]. Functional SNPs may influence the expression of EGF or it's receptors in several different tumors, as described by Nomura et al. [8]. The predictive value of the EGF + $61 \mathrm{~A}>\mathrm{G}$ polymorphism in colorectal cancer has been described in previous studies, where an increased response were shown in patients with the EGF61A/G genotype compared with EGF61 homozygous patients, when treated with capecitabine and oxaliplatine [9]. However in lung cancer, there is only a limited knowledge of the prognostic and predictive value of the EGF-system.

The DNA-excision repair system is known to be of importance in the treatment with platinum based chemotherapy, as up regulation of the system may improve the clearing of DNA-adducts induced by the chemotherapy and hence a decreased response [10]. As platinum based chemotherapy represents the cornerstone of treatment in lung cancer, alterations of the genes involved in these pathways, may provide important information of response. Despite inconsistent results in studies investigating SNPs within the DNA-excision repair system in lung cancer as well as other cancers, it has considerable interest and hold promise as predictive marker.

The Vascular Endothelial Growth Factor (VEGF) system is essential to tumor growth and development [11] and tumors larger than 1 millimeter are depending on angiogenesis for growth and survival $[12,13]$. Deregulation of VEGF expression and its receptors are frequently seen in human tumors, including NSCLC [14] and different SNPs are found to be correlated with changes in the expression of VEGF [15]. Several stud- ies of VEGF SNPs and their role in different cancers have been performed, but the results are equivocal. In breast cancer, homozygozity of VEGF+405 and -460 appears to be associated with increased tumor aggressiveness and reduced progression free survival (PFS) [16]. In prostate cancer there seems to be some evidence of VEGF-460 alterations and correlation to the risk of cancer, prognosis and tumor aggressiveness, but different studies show contradictory results $[16,17]$. In colorectal cancer an association between the VEGF $+405 \mathrm{C}$ allele and reduced risk of colorectal cancer together with prolonged overall survival (OS) has been shown $[18,19,20]$. A Japanese study showed that the VEGF -460 CC genotype was associated with low differentiation of the tumor and thus poor prognosis [21]. The relationship between VEGF +405 and VEGF-460 and their functional influence on the VEGF-A protein levels in normal colorectal tissue have been investigated, and found to have possible clinical implications [22]. The development of drugs targeting the VEGFsystem has increased the clinical interest in markers within the system. There is only sparse knowledge on the prognostic importance of SNPs in the VEGF-system in lung cancer. The possible predictive value has not yet been investigated.

The aim of the present study was to identify a possible predictive value of SNPs in the EGF-system, DNA-excision repair system and VEGF-system in lung cancer with response as the primary endpoint and progression free survival (PFS) and overall survival (OS) as secondary endpoints. A panel of 17 SNPs was initially investigated in a hypothesis generating study, and any significant results were subsequently investigated in an independent validation cohort. When relevant, haplotypes were generated and investigated with respect of the same endpoints.

\section{Material and Methods}

The present study consists from two separate, prospective trials, one hypothesis generating and one validating.

\subsection{Patients and Treatment}

Two independent patient materials were evaluated. Firstly, a test cohort of 100 patients was included. Secondly, another 200 patients were subsequently included as the validation cohort. All patients met the same inclusion criteria, consisting of histopathologically verified NSCLC, stage III-IV disease, no previous chemotherapy and a performance status allowing chemotherapy. The patients were treated with first-line chemotherapy. Palliative radiotherapy was given when indicated. The 
treatment consisted of Carboplatin (dose based on AUC and renal function, given i.v. at day 1 every third week) in combination with Vinorelbine $\left(30 \mathrm{mg} / \mathrm{m}^{2}\right.$ i.v. day 1 followed by $30 \mathrm{mg} / \mathrm{m}^{2}$ i.v. or $60 \mathrm{mg} / \mathrm{m}^{2}$ p.o. day 8 everythird week) for a maximum of 6 cycles. The primary endpoint of this study was response rate (RR). Objective response was evaluated according to RECIST 1.0 criteria, by a CT of chest and the upper abdomen after every second cycle [23]. Secondary endpoints were PFS and OS. Pre-treatment blood samples were collected and used for biomarker analyses and all patients had a baseline CT of chest and the upper abdomen within one month before treatment start. Written informed consent was obtained before inclusion and the study was conducted in accordance with Danish law after approval by the Regional Ethics Committee.

\subsection{Single Nucleotide Polymorphism Analyses}

Before treatment start a peripheral venous whole blood sample was collected. DNA was extracted through purification of the sample by Maxwell 16 Genomic DNA Purification Kits ${ }^{\circledR}$, according to the manufacturers' instructions (Promega Corporation, Madison, WI, USA). The allelic composition of the different SNPs were investigated by real-time polymerase chain reaction (PCR) performed on an ABI 7900 HT fast Real Time PCRsystem (Applied Biosystems, Foster City, CA, USA).
Seventeen different SNPs were characterized (Table 1). Commercial assays (Applied Biosystems) (Table 1) were available for all but one SNP (SP1-216 (EGFR)), and hence primers and probes were designed for this very purpose. The primer sequence was cgtccgggcagccc (forward) and ggcgctcacaccgtgc (reverse). The corresponding probes were 6FAM-agcagcetccgec and VIC-agcagcctcctcc. $2 \mu \mathrm{l}$ of DNA and 8 or $18 \mu \mathrm{l}$ of $2 \mathrm{x}$ TaqMan Genotyping master mix (Applied Biosystems), genotyping assay and water were added in each well of a 96 well micro titer plate and subsequently the PCR analyses were run under standard circumstances. After finishing the standard PCR, an allelic discrimination post-read run was performed.

\subsection{Statistics}

Hardy Weinberg equilibrium was evaluated by Chisquare statistics. Fisher's exact test was used for comparison of response rates according to genotype. Haplotypes of each individual were estimated using a Bayesian approach applied in the algorithm of the PHASE program (version 2.1) developed by Stephens et al. [24]. Survival analyses were performed using the Kaplan-Meier method and differences according to genotypes were calculated using the Log Rank test. Hazard Ratios were based on the Mantel-Haenszel method.

Table 1. SNPs classified by functional system and corresponding assay number (Applied Biosystems).

\begin{tabular}{|c|c|c|c|c|c|c|}
\hline Functional system & \multicolumn{2}{|l|}{ EGF } & \multicolumn{2}{|c|}{ DNA-EXCISION REPAIR } & \multicolumn{2}{|l|}{ VEGF } \\
\hline & SNP & rs & SNP & rs & SNP & rs \\
\hline & EGF 61 & 4444903 & ERCC1 -118 & 11615 & VEGF +405 & 2010963 \\
\hline \multirow[t]{2}{*}{ Assay } & \multicolumn{2}{|l|}{ c_27031637_10 } & \multicolumn{2}{|l|}{ c_2532959_1_ } & \multicolumn{2}{|l|}{ c__8311614_10 } \\
\hline & SP 1-(216) EGFR & 712829 & ERCC1 C8092A & 3212986 & VEGF -460 & 833061 \\
\hline \multirow[t]{2}{*}{ Assay } & \multicolumn{2}{|l|}{ Not available * } & \multicolumn{2}{|l|}{ c__2532948_10 } & \multicolumn{2}{|l|}{ c__1647381_10 } \\
\hline & EGFR R521K & 2227983 & XPD 751 & 13181 & VEGF +936 & 3025039 \\
\hline Assay & \multicolumn{2}{|l|}{ c_16170352_20 } & \multicolumn{2}{|l|}{ c__3145033_10 } & \multicolumn{2}{|l|}{ c_3025039_10 } \\
\hline & KRAS 3636 & 13096 & CCND1 A870G & 9344 & VEGF -2578 & 699947 \\
\hline Assay & \multicolumn{2}{|l|}{ c_26578457_10 } & \multicolumn{2}{|l|}{ c__ 744725_1_ } & \multicolumn{2}{|l|}{ c__8311602_10 } \\
\hline & & & $\mathrm{XRCC1}$ & 25487 & VEGF -1154 & 1570360 \\
\hline Assay & & & c__622564_10 & & c__1647379_10 & \\
\hline & & & & & VEGFR2 Q472H & 1870377 \\
\hline \multirow[t]{2}{*}{ Assay } & & & & & \multicolumn{2}{|l|}{ c_11895315_20 } \\
\hline & & & & & VEGFR2 V297I & 2305948 \\
\hline \multirow[t]{2}{*}{ Assay } & & & & & \multicolumn{2}{|l|}{ c__22271999_20 } \\
\hline & & & & & VEGFR2 -604 & 2071559 \\
\hline Assay & & & & & c_15869271_10 & \\
\hline
\end{tabular}


Table 2. Patient characteristics at baseline (both cohorts).

\begin{tabular}{|c|c|c|c|c|}
\hline \multirow[b]{2}{*}{ Characteristic } & \multicolumn{4}{|c|}{ Patient characteristics (baseline) } \\
\hline & $\begin{array}{c}\text { Number of } \\
\text { Patients } \\
\text { (Test cohort } \\
n=87 \text { ) }\end{array}$ & $\%$ & $\begin{array}{c}\text { Number of } \\
\text { Patients } \\
\text { (Validation } \\
\text { cohort } n= \\
161 \text { ) }\end{array}$ & $\%$ \\
\hline \multicolumn{5}{|c|}{ Age at inclusion (years) } \\
\hline Median (range) & $65(40-80)$ & & $65(41-80)$ & \\
\hline \multicolumn{5}{|l|}{ Sex } \\
\hline Male & 57 & 66 & 93 & 58 \\
\hline Female & 30 & 34 & 68 & 42 \\
\hline \multicolumn{5}{|l|}{ Histology } \\
\hline Adenocarcinoma & 48 & 55 & 103 & 64 \\
\hline $\begin{array}{l}\text { Squamous cell } \\
\text { carcinoma }\end{array}$ & 30 & 35 & 43 & 27 \\
\hline $\begin{array}{l}\text { Large cell carci- } \\
\text { noma }\end{array}$ & 3 & 3 & 5 & 3 \\
\hline Others & 6 & 7 & 10 & 6 \\
\hline \multicolumn{5}{|l|}{ Stage } \\
\hline II & 0 & 0 & 2 & 1 \\
\hline III & 24 & 28 & 37 & 23 \\
\hline IV & 63 & 72 & 122 & 76 \\
\hline \multicolumn{5}{|c|}{ Distant metastasis* } \\
\hline Yes & 30 & 34 & 91 & 57 \\
\hline No & 57 & 66 & 70 & 43 \\
\hline \multicolumn{5}{|l|}{ CNS metastasis } \\
\hline Yes & 10 & 11 & 14 & 9 \\
\hline No & 77 & 89 & 147 & 91 \\
\hline \multicolumn{5}{|l|}{ Previous surgery } \\
\hline Yes & 5 & 6 & 2 & 1 \\
\hline No & 82 & 94 & 159 & 99 \\
\hline \multicolumn{5}{|l|}{ Radiotherapy } \\
\hline Yes & 22 & 25 & 34 & 21 \\
\hline No & 65 & 75 & 127 & 79 \\
\hline \multicolumn{5}{|c|}{ Performance status (baseline) $\dagger$} \\
\hline $0-1$ & 76 & 87 & 140 & 87 \\
\hline 2 & 11 & 13 & 21 & 13 \\
\hline \multicolumn{5}{|l|}{ Number of cycles } \\
\hline Median (range) & $4(1-6)$ & & $4(1-6)$ & \\
\hline \multicolumn{5}{|c|}{ Response (RECIST 1.0) } \\
\hline $\mathrm{CR}$ & 1 & 1 & 1 & 1 \\
\hline PR & 26 & 30 & 33 & 20 \\
\hline SD & 42 & 48 & 96 & 60 \\
\hline $\mathrm{PD}$ & 11 & 13 & 18 & 11 \\
\hline NDt & 7 & 8 & 13 & 8 \\
\hline
\end{tabular}

*Significantly different, $\mathrm{p}=0.0013$ (Fishers' Exact test), $\uparrow \mathrm{ECOG}, \ddagger \mathrm{ND}=$ Not available fore response evaluation due to death or discontinued treatment.
Response included complete and partial response versus no change or progression. Progression free survival was defined as time from first day of treatment until date of objective progression or death. Overall survival was defined as time from first day of treatment until death. All statistical calculations were carried out using the NCSS statistical software (NCSS Statistical Software, Kaysville, UT, USA, version 07.1.15, 2009).

\section{Results}

\subsection{Patient Characteristics}

Table 2 shows the patient characteristics. Eighty-seven patients were included in the test cohort, and 161 in the validation cohort. The two cohorts were compared in accordance to patient characteristics. The only significant difference was the number of patients diagnosed with distant metastasis, which was significantly higher in the validation cohort $(p=0.0013)$, but there were no significant differences in stage distribution.

In the test cohort, the population consisted of 57 men and 30 women with a median age of 65 years (range 40-80). Seven patients were not evaluable for response as a consequence of death or discontinued treatment due to impaired general health condition, and were only included in the survival analyses. All but one SNP (the CCND1 A870G) were in Hardy Weinberg equilibrium. At the end of the study, 9 patients were still alive and were censored. The clinical parameters and their relation to response were investigated. The only parameters that correlated with response were performance status and stage of disease.

In the validation cohort, 161 patients were included; 93 males and 68 females with a median age of 65 years (range 41-80). Thirteen patients were not available for response evaluation, for the same reasons as mentioned above, and were only included in the survival analyses. Two patients with stage II disease were included as they were candidates for chemotherapy. The SNPs investigated in the validation cohort were in Hardy Weinberg equilibrium. At the end of the study, 146 patients had experienced progressive disease. Fifty-one patients were still alive at the end of the study.

All of the patients received at least one cycle of chemotherapy, with a median of 4 (range 1-6). Only patients receiving at least two cycles of chemotherapy were considered available for response evaluation. Patients receiving only one cycle were included in the survival analysis.

\subsection{The Predictive Value of the SNPs}

None of the SNPs with relation to the EGF-system correlated to response rate (data not shown). The same ap- 
plied to the SNPs in the DNA-excision repair system. On the other hand, in the VEGF-system, a significant correlation between some of the SNPs investigated and response was detected. Patients being VEGF +405 heterozygous $(\mathrm{G} / \mathrm{C}, 42 \%)$ had a significantly higher $\mathrm{RR}$ (47\%) compared to the homozygous $(\mathrm{G} / \mathrm{G}$ and $\mathrm{C} / \mathrm{C}$ $(58 \%), \mathrm{RR}=24 \%, \mathrm{p}=0.035)$. The same applied to the $\mathrm{VEGF}-460 \mathrm{C} / \mathrm{T}(\mathrm{RR}=47 \%, \mathrm{p}=0.035)$ as demonstrated in Table 3. The VEGF-460 and the VEGF -2578 were in almost complete linquage disequilibrium (LD) (86 of 87 patients) and the findings for VEGF -2578 were hence similar to those for VEGF -460. In the VEGFR-2 gene there were some tendencies of altered response according to genotype (data not shown), but the sample sizes of some of the groups were very small, making the results unreliable.

The SNPs with significant association to response were further evaluated in the validation cohort. Due to the high LD between VEGF -460 and the VEGF -2578 , the genotypes of VEGF -2578 were not examined. No significant associations were detected, as RR for VEGF +405 CC or GG versus CG was $27 \%$ and $18 \%$ respectively $(p=0.24)$ and $21 \%$ versus $26 \%$ in favor of the heterozygous genotype in VEGF $-460(\mathrm{p}=0.56)$. Validation of the results from the test cohort was thus not possible.

\subsection{Haplotype Analysis and Response}

Since both VEGF $+405 \mathrm{G} / \mathrm{C}$ and $-460 \mathrm{C} / \mathrm{T}$ turned out with a significant correlation to response, and are known to be closely related in the gene, their combined effect was further evaluated in haplotypes, which were estimated in the PHASE program, resulting in three different haplotypes with a frequency above $0.05 \%$. The response rates for patients carrying the haplotype combination resulting in heterozygozity of both of the VEGF +405 and VEGF - 460 SNPs (24 patients $(30 \%)$ ) compared to all other possible combinations (56 patients $(70 \%)$ ) were investigated. In the test cohort, the RR was $50 \%$ in favor of the haplotype combination GC/CT and $27 \%$ for all other combinations. The p-value was 0.07 and thus marginally significant, suggesting a favorable response when carrying this haplotype combination (Table 4).

In the validation cohort, 43 patients $(29 \%)$ hosted the GC/CT haplotype combination. However there was no indication of a higher response rate in this subgroup as the RR for GC/CT was $17 \%$ versus $26 \%$ in all other combinations $(p=0.28)$.

\subsection{Survival Analyses}

The median PFS in the test cohort was 169 days (95\% CI 140-174) and the median OS was 277 days (95\% CI, 212-360). The survival data according to genotype of all
Table 3. SNPs and response (test cohort).

\begin{tabular}{|c|c|c|c|c|c|}
\hline SNP & Response & $\begin{array}{c}\text { No } \\
\text { Response }\end{array}$ & \multicolumn{2}{|c|}{$\begin{array}{l}\text { Response } \\
\text { Rate }(\%)\end{array}$} & Results \\
\hline \multicolumn{5}{|l|}{$V E G F+405$} & \multirow{4}{*}{$\begin{array}{l}\text { Response vs. } \\
\text { No response } \\
\text { GC }>\text { GG } \\
+C C \\
(\mathrm{p}=0.035)\end{array}$} \\
\hline $\mathrm{GG}(\mathrm{n}=41)$ & 10 & 31 & 24 & \multirow{2}{*}{24} & \\
\hline $\mathrm{CC}(\mathrm{n}=5)$ & 1 & 4 & 20 & & \\
\hline $\mathrm{GC}(\mathrm{n}=34)$ & 16 & 18 & 47 & 47 & \\
\hline \multicolumn{5}{|l|}{ VEGF-460 } & \multirow{4}{*}{$\begin{array}{l}\text { Response vs } \\
\text { No response } \\
\mathrm{CT}>\mathrm{CC}+\mathrm{TT} \\
(\mathrm{p}=0.035)\end{array}$} \\
\hline $\mathrm{CC}(\mathrm{n}=32)$ & 7 & 25 & 22 & 2 & \\
\hline $\mathrm{TT}(\mathrm{n}=14)$ & 4 & 10 & 29 & 24 & \\
\hline $\mathrm{CT}(\mathrm{n}=34)$ & 16 & 18 & 47 & 47 & \\
\hline \multicolumn{6}{|l|}{ VEGF-2578 } \\
\hline $\mathrm{CC}(\mathrm{n}=14)$ & 4 & 10 & 29 & \multirow{2}{*}{24} & \multirow{3}{*}{$\begin{array}{l}\text { Response vs. } \\
\text { No response: } \\
\mathrm{CA}>\mathrm{CC} \\
+\mathrm{AA}(\mathrm{p}= \\
0.058)\end{array}$} \\
\hline $\mathrm{AA}(\mathrm{n}=31)$ & 7 & 24 & 23 & & \\
\hline $\mathrm{CA}(\mathrm{n}=35)$ & 16 & 19 & 46 & 46 & \\
\hline
\end{tabular}

Table 4. VEGF + 405 and - 460 haplotypes and response.

(a) Test cohort

\begin{tabular}{ccccc}
\hline $\begin{array}{l}\text { Haplotype } \\
\text { combination }\end{array}$ & $\begin{array}{l}\text { Re- } \\
\text { sponse }\end{array}$ & $\begin{array}{l}\text { No } \\
\text { Re- } \\
\text { sponse }\end{array}$ & $\begin{array}{l}\text { Response } \\
\text { Rate (\%) }\end{array}$ & Results \\
\hline $\begin{array}{c}\text { GC/CT } \\
(\mathrm{n}=24)\end{array}$ & 12 & 12 & 50 & $\begin{array}{c}\text { Response } \\
\text { vs. No re- } \\
\text { sponse: } \\
\text { All other }\end{array}$ \\
$\begin{array}{c}\text { combina- } \\
\text { tions* } \\
(\mathrm{n}=56)\end{array}$ & 15 & 41 & 27 & $\begin{array}{c}\text { other } \\
(\mathrm{p}=0.07)\end{array}$ \\
\hline
\end{tabular}

(b) Validation cohort

\begin{tabular}{ccccc}
\hline $\begin{array}{c}\text { Haplotype } \\
\text { combination }\end{array}$ & Response & $\begin{array}{c}\text { No } \\
\text { Re- } \\
\text { sponse }\end{array}$ & $\begin{array}{c}\text { Response } \\
\text { Rate (\%) }\end{array}$ & Results \\
\hline $\begin{array}{c}\text { GC/CT } \\
(\mathrm{n}=42)\end{array}$ & 7 & 27 & 17 & $\begin{array}{c}\text { Response } \\
\text { vs. No } \\
\text { response: } \\
\text { All other } \\
>\text { GC/CT } \\
(p= \\
\text { All other }\end{array}$ \\
$\begin{array}{c}\text { combinations* } \\
(\mathrm{n}=106)\end{array}$ & 35 & 79 & 26 & $0.29)$ \\
\hline
\end{tabular}

*Four different haplotypes (CG, CC, TG, TC) resulting in ten possible combinations.

of the examined SNPs were investigated in the test cohort. No significant associations between either the EGF or the DNA-excision repair SNPs and PFS were found. However, as it appears from Figure 1, the VEGF-460 $\mathrm{C} / \mathrm{T}$ and VEGF $-2578 \mathrm{C} / \mathrm{A}$ were significantly related to an increased PFS. The median PFS for VEGF $-460 \mathrm{C} / \mathrm{T}$ was 176 days (95\% CI 165-247) compared to 140 days (95\% CI 89-169) for the $\mathrm{C} / \mathrm{C}$ and $\mathrm{T} / \mathrm{T}$ genotypes ( $\mathrm{p}=$ 0.024, HR:0.61, 95\% CI 0.39-0.94). Patients carrying the C/A genotype of VEGF -2578 also had a statistically 
significantly improved median PFS of 176 days (95\% CI 169-247) compared to the $\mathrm{C} / \mathrm{C}$ and $\mathrm{A} / \mathrm{A}$ genotypes who had a median PFS of 140 days $(95 \%$ CI $85-169)(\mathrm{p}=$ 0.013, HR: $0.58,95 \%$ CI $0.38-0.90$ ). The same trend was observed for VEGF +405 with a median PFS of heterozygous of 173 days (95\% CI 163-185) and 141 days (95\% CI 89-172) for the homozygous, but this was not significant ( $\mathrm{p}=0.13$, HR:0.72, 95\% CI 0.47-1.11).

In the validation cohort, the median PFS was 154 days (95\% CI 135-170) and the median OS was 245 days (95\% CI 190-313). Only survival data for VEGF +405 and -460 was investigated. There were no significant associations for PFS and OS respectively, in either of the SNPs investigated. The median PFS for VEGF +405 was 154 days $(95 \%$ CI $133-172)$ and 147 days $(95 \%$ CI 125-174) in favor of the heterozygous ( $\mathrm{p}=0.84$, HR:0.97, 95\% CI 0.70-1.34). In VEGF -460 the median PFS was 154 days (95\% CI 118-172) and 158 (95\% CI 135-173) with a p-value of 0.5 (HR: $0.89,95 \%$ CI $0.64-1.24$ ) in favour of the homozygous. 150 days (95\% CI 93-169) in favor of the haplotype combination providing bi-allelic heterozygozity ( $p=0.027$, HR: $0.59,95 \%$ CI: $0.38-0.92$ )

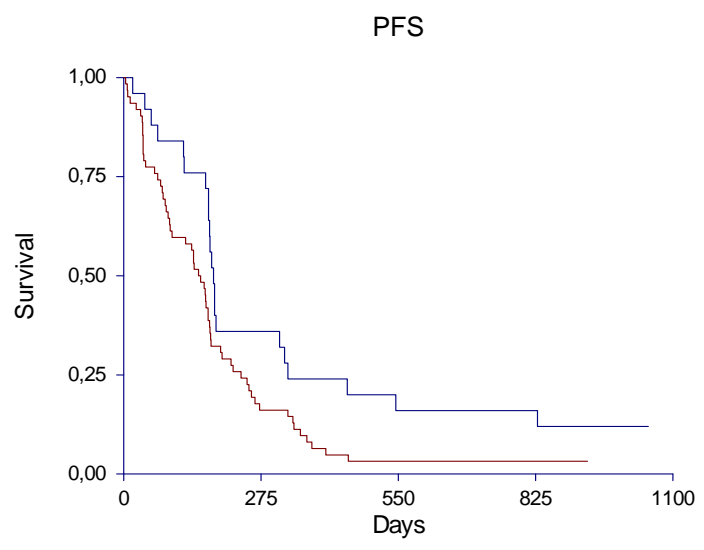

(a) VEGF $+405 ; \mathrm{p}=0.13$, HR: $0.72(95 \%$ CI $0.47-1.11)$

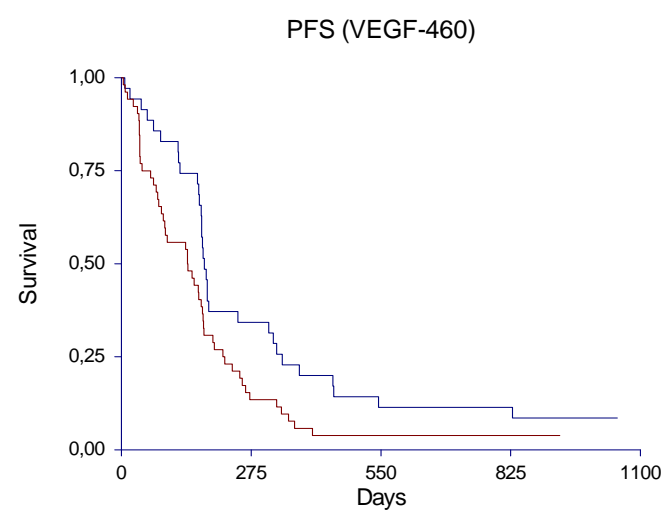

(b) VEGF-460; $\mathrm{p}=0.024$, HR: $0.61(95 \%$ CI 0.39-0.94)

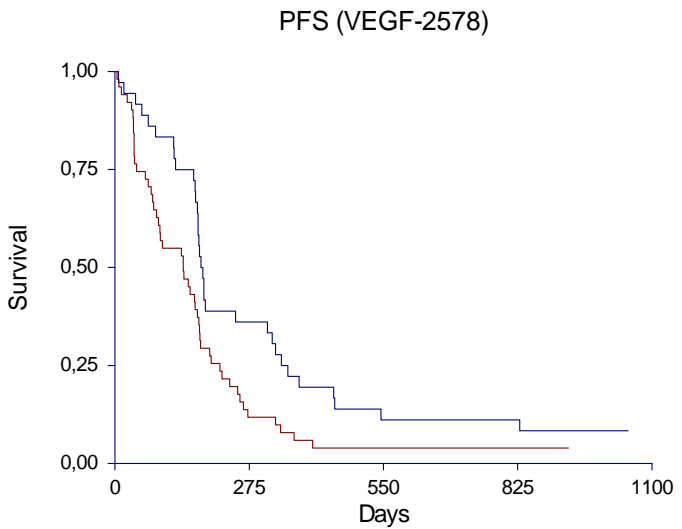

(c) VEGF-2578; $p=0.013$, HR: 0.58 (95\% CI 0.38-0.90)

Figure 1. Progression free survival (test cohort). Kaplan Meier survival curves according to genotype. The blue lines represent heterozygote patients and the red line represents homozygote patients. Number of patients $(n)=87$.

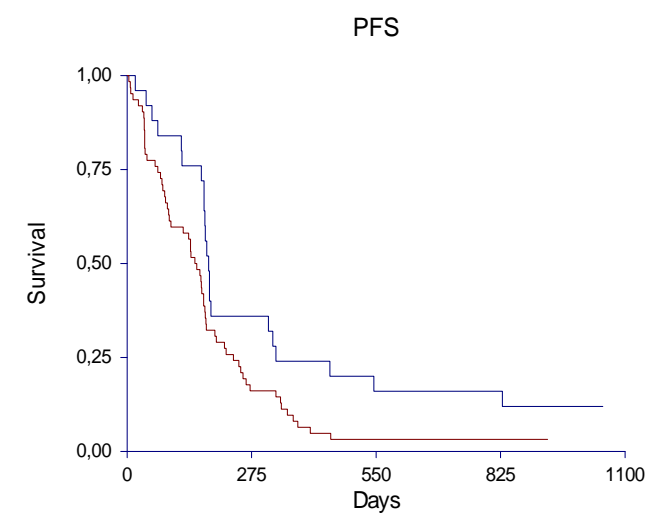

(a) Test cohort $(\mathrm{n}=87) ; \mathrm{p}=0.027$, HR: $0.59(0.38-0.92)$

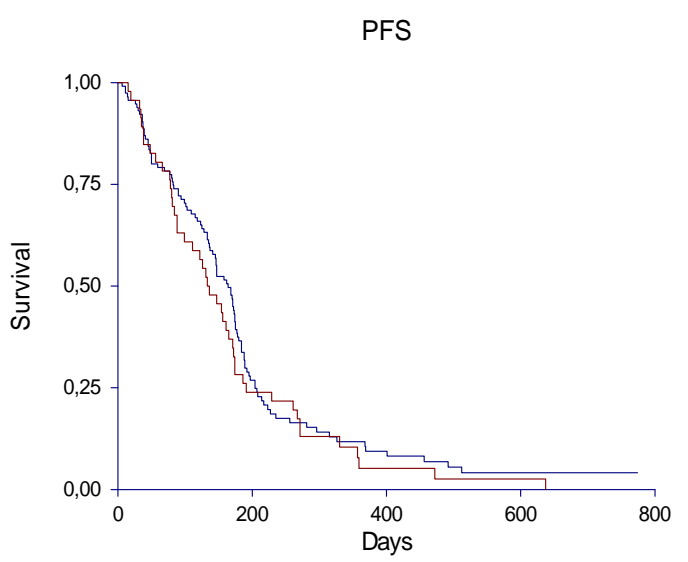

(b) Validation cohort $(\mathrm{n}=161), \mathrm{p}=0.36$, HR: 0.85 (95\% CI 0.59-1.22)

Figure 2 (a-b): Kaplan Meier survival curves according to haplotype combination. The blue line represents the CG/TC combination and the red line represents all other combinations. 
was demonstrated. The correlation was not confirmed in the validation cohort (Figure 2).

Neither SNPs nor haplotypes significantly affected the median OS in the test or the validation cohort (data not shown).

\section{Discussion}

With several new treatment options emerging in the treatment of lung cancer, the possibility of individualizing, and hopefully improving the treatment strategies, are attractive. This, however, calls for reliable markers of response to conventional therapies as well as new treatment strategies. Several markers have been investigated, but it should be noticed that many results are based on small studies, increasing the risk of false positive results as also shown in the present study.

As opposite to most other studies, our results were based on a test cohort with further analysis of the significant markers in a validation cohort.

The SNPs represented three different biological systems, known from previous studies to be involved in response to chemotherapy and carcinogenesis. Furthermore, they hold promise of development of new biological treatments. Investigation of functional SNPs provide a patient friendly and cost-efficient way of identifying biomarkers, and their possible use as predictive markers are thus advantageous in several respects.

The EGF-system is involved in carcinogenesis, and different SNPs may hold predictive or prognostic information. New biological treatments such as monoclonal antibodies and tyrosine kinase inhibitors, targeting the EGF-system, are being developed, but several studies stresses the fact that only a limited patient population seems to benefit from these treatments $[25,26]$. Some markers of response, such as mutational status in the downstream signaling pathways, have been identified, but investigating these markers requires tumor tissue and extensive analysis, why less invasive and time consuming methods are highly warranted.

In the present study, four different SNPs were investigated, but none of them were correlated with response, PFS or OS. There is sparse knowledge on the prognostic value of the EGF-system in lung cancer. One previous study on the prognostic value of $\mathrm{EGF}+61 \mathrm{~A}>\mathrm{G}$ among Korean patients with NSCLC, also failed to show any significant correlations [27]. The fact that the previous study only included Korean patients makes the results less transferable to our population, but still, supports our findings. The predictive value of SNPs in lung cancer has not been described previously. In colorectal cancer, Spindler et al., found the EGF $+61 \mathrm{~A} / \mathrm{G}$ genotype associated with an increased response when treated with capecitabine and oxaliplatine [9]. Patients with
NSCLC are also treated with platinum based chemotherapy, but still different cancers are known to host different biological and functional characteristics, making transferring of results from one cancer to another dubious. SNPs in the EGF system though still remains an interesting possible marker, as new treatments targeting the EGF-system are evolving.

The DNA-repair system has been examined more extensively, both in NSCLC and other malignant diseases. Previous studies have demonstrated a relationship between expression levels and response to chemotherapy, suggesting a higher degree of DNA-adduct clearance among patients with high expression, when treated with platinum based chemotherapy and thus decreased effect of the chemotherapy [28]. This was also demonstrated in a small case-control study on lung cancer patients [29]. We investigated five SNPs in genes involved in the DNA-repair system, under the hypothesis that even small alterations in the functional part of the gene, may affect the expression level and hence the response to chemotherapy. We were, however, not able to confirm this hypothesis, as no significant correlations were detected. Previous studies also shows contradictory results, further illustrating the complexity of this system. The prognostic value of SNPs has only been sparsely investigated, but a high expression of the ERCC1 gene shows potential as a beneficial prognostic marker [30]. The predictive value was investigated by Isla et al. who found an association between the homozygoty of $\mathrm{C} / \mathrm{C}$ in ERCC1-118 and increased overall survival among NSCLC-patients treated with Docetaxel and Cisplatin, suggesting that another treatment regimen might be more effective in the alternative genotypes [31]. Kalikaki et al., managed to demonstrate an increased response among patients with one or two $\mathrm{C}$ alleles when treated with platinum-based chemotherapy as first or second line, but no effect on survival was detectable [32]. We found no such association. This might be explained by the small numbers of patients in the Isla study (62 patients) and in our study (87 patients), combined with the high number of analyses, composing a risk of finding significant associations only by chance. Furthermore, different chemotherapy regimens were used, making the two populations less comparable. Another study by Camps et al., investigated the XPD 751 and the XPD 312 SNPs and their relation to response in Gemcitabine and Cisplatin treated patients, but also failed to detect any significant correlations [33]. This is in accordance with our findings, although again, the chemotherapy regimens are not fully comparable, and the number of patients was small.

SNPs in the VEGF system and their role as predictive or prognostic markers have also been investigated in 
different trials and cancers, however very sparsely in NSCLC. In the test cohort, we were able to demonstrate a significant relation between SNPs in the VEGF system, response and survival. The VEGF $+405 \mathrm{G} / \mathrm{C},-460 \mathrm{C} / \mathrm{T}$ and $-2578 \mathrm{C} / \mathrm{A}$ all showed a significant relationship with increased response, compared to the other alleles, and may serve as predictive markers. This is the first study to evaluate the predictive value of VEGF SNPS in lung cancer.

In order to further evaluate the predictive potential by examining the combined effect of the relevant SNPs, we investigated the haplotype combination ( $\mathrm{CG}$ and $\mathrm{TC}$ ) providing heterozygozity in both SNPs and found that the tendency of improved response among patients with bi-allelic heterozygozity remained. The benefits of generating haplotypes from closely related SNPs and subsequently investigating their combined effect, has been demonstrated previously (Hansen et al) The close relationship between VEGF +405 and VEGF -460 is well known, and is also demonstrated in the HapMap project [34], justifying the generation of haplotypes from these two SNPs. Haplotypes have been sparsely investigated, and when done, mostly in light of a single allele and its functional impact. The combination of haplotypes however, seems to be a reasonable approach, considering our bi-allelic nature. When estimating haplotypes, we only included the VEGF -460 and the +405 SNPs, even though the VEGF -2578 SNP also showed significant relationship with response and PFS in the test cohort. This was justified by the fact that since almost complete LD between VEGF - 460 and VEGF - 2578 exists, adding VEGF -2578 to the haplotype, would provide us with no further information.

For the SNPs associated with an improved response rate in the test cohort, we were also able to demonstrate a significant (VEGF-460 and -2578) or borderline significant (VEGF +405) increase in PFS, when heterozygous. A significantly improved PFS was also demonstrated for the haplotype combination providing bi-allelic heterozygosis and is thus in consistency with the SNP results. The OS was not related to any of the polymorphisms or haplotypes, but PFS is considered a valid estimate of the treatment effect as it is not influenced by subsequent treatment regimens. The prognostic value of SNPs in the VEGF-system in NSCLC has previously been investigated. A large study by Zhai et al. failed to demonstrate any general prognostic value of the VEGF $+405,-460$ and +936 SNPs among patients developing lung cancer, compared with controls without lung cancer[35]. In a subsequent study, Heist et al. however showed an increased OS for patients harboring the C-allele of VEGF +405among patients with early stage NSCLC which was surgically resected. [36, 35].
Neither SNP investigated in the present study was related to any differences in OS, but our patients differed from the two other studies as they were in an advanced stage of disease and treated by chemotherapy, thus decreasing the comparability of the studies. These diverging results are neither novel nor unexpected, considering findings in other studies in the area of breast cancer, prostate cancer and lung cancer [16,37,17,35]. It seems likely that the same alterations in the same SNPs are related to diverse functional consequences in different cancers, but the biological conditions for this remains unknown.

Validation of the results from the test cohort was not possible. There are several plausible reasons for this. Firstly, although very similar and thus comparable, the patient material was fairly small, with only 87 patients in the test cohort and 161 in the validation cohort. In the test cohort, multiple testing was performed, increasing the risk of finding significant results only by chance, which may explain why the results were not confirmed in the independent validation cohort. On the other hand, the SNPs found to be significantly associated with increased response rates and PFS, are the same as found significant in previous studies in colorectal, breast and prostate cancer $[16,37,17,35]$, which could support our results from the test cohort. Despite these arguments, we can not ignore the fact that no correlations were detectable in the validation cohort, bringing us to the conclusion that there seems to be no predictive value of the SNPs investigated in this study, and the outcome in chemotherapy treated patients with NSCLC.

Our study is one of the first evaluating the predictive value of the VEGF-system in NSCLC, and the obvious advantages of including a validation cohort further strengthen our results. Even though negative, our findings brings further light to the area of predictive markers in NSCLC.

The only association found, was in the VEGF system, but validation of the results was not possible, and hence we are urged to reject the hypothesis of a predictive value of the investigated SNPs in NSCLC, which for the EGF-system and DNA-repair system are in concordance with some previous studies. The quest of identifying independent and reliable predictive markers in NSCLC requires further investigation in larger patient samples and the present study again stresses the fact that results from small populations should be interpreted with caution.

In conclusion, our results do not indicate that polymorphisms within three different biological systems are useful as predictive markers, but underline the crucial importance of independent validation to avoid erroneous conclusions. 


\section{Acknowledgements}

We express thanks to Yvette Schandorf Sorensen for collecting and keeping track of patient data. We also thank Karin Larsen for proofreading and Lone Frischknecht, Pia Nielsen and Lone Hartmann for their technical support. Further, we are grateful to Professor Steen Kølvraa for his wise guidance in the area of genetics.

\section{REFERENCES}

[1] S. S. Hecht, "Tobacco Smoke CarciNogens and Lung Cancer," Journal of the National Cancer Institute, Vol. 91, No. 14, 1999, pp. 1194-1210.

[2] P. Jacoulet, J. L. Breton, V. Westeel, M. Mercier, G. Garnier and A. Depierre, "Phase I Study of ViNorelbine and Carboplatin in Advanced Non-small Cell Lung Cancer," Lung Cancer, Vol. 12, No. 3, 1995, pp. 247-257.

[3] C. Santomaggio, E. Tucci, M. Rinaldini, R. Algeri, R. Righi, F. Pepi, P. Ghezzi, A. Andrei and A. Bellezza, "Carboplatin and ViNorelbine in the Treatment of Advanced Non-small-cell Lung Cancer: a Multicenter Phase II Study," American Journal of Clinical Oncology, Vol. 21, No. 1, 1998, pp. 67-71.

[4] N. Helbekkmo, S. H. Sundstrom, U. Aasebo, P. F. Brunsvig, Plessen C. von, H. H. Hjelde, O. K. Garpestad, A. Bailey and R. M. Bremnes, "ViNorelbine/Car- boplatin vs Gemcitabine/Carboplatin in Advanced NSCLC Shows Similar Efficacy, but Different Impact of Toxicity," British Journal of Cancer, Vol. 97, No. 3, 2007, pp. 283-289.

[5] Masters, G., "Carboplatin and ViNorelbine in Advanced Non-small Cell Lung Cancer: A Phase I/II Study," Oncologist., Vol. 6 Suppl 1, 2001, pp. 12-15.

[6] Harmon, D. L., Shields, D. C., Woodside, J. V., McMaster, D., Yarnell, J. W., Young, I. S., Peng, K., Shane, B., Evans, A. E., and Whitehead, A. S., "Methionine Synthase D919G Polymorphism is a Significant but Modest Determinant of Circulating Homocysteine Concentrations," Genetic Epidemiology., Vol. 17, No. 4, 1999, pp. 298-309.

[7] D. S. Salomon, R. Brandt, F. Ciardiello and N. NormanNo, "Epidermal Growth Factor-related Peptides and Their Receptors in Human Malignancies," Critical Reviews in Oncology/Hematology, Vol. 19, No. 3, 1995, pp. 183-232.

[8] M. Nomura, H. Shigematsu, L. Li, M. Suzuki, T. Takahashi, P. Estess, M. Siegelman, Z. Feng, H. Kato, A. Marchetti, J. W. Shay, M. R. Spitz, I. I. Wistuba, J. D. Minna and A. F. Gazdar, "Polymorphisms, Mutations, and Amplification of the EGFR Gene in Non-small Cell Lung Cancers," PLoS. Medicine, Vol. 4, No. 4, 2007, pp. e125.

[9] K. L. Spindler, R. F. Andersen, L. H. Jensen, J. Ploen and A. Jakobsen, "EGF61A $>$ G Polymorphism as Predictive Marker of Clinical Outcome to First-line Capecitabine and Oxaliplatine in Metastatic Colorectal Cancer," Annual Oncology, 2009.
[10] P. J. McHugh, V. J. Spanswick and J. A. Hartley, "Repair of DNA Interstrand Crosslinks: Molecular Mechanisms and Clinical Relevance," Lancet Oncology, Vol. 2, No. 8, 2001, pp. 483-490.

[11] P. Carmeliet and R. K. Jain, "Angiogenesis in Cancer and Other Diseases," Nature, Vol. 407, No. 6801, 2000, pp. 249-257.

[12] N. Ferrara, H. P. Gerber and J. LeCouter, "The Biology of VEGF and Its Receptors," Nature Medicine, Vol. 9, No. 6, 2003, pp. 669-676.

[13] J. Folkman, "What is the Evidence that Tumors are Angiogenesis Dependent?" Journal of the National Cancer Institute, Vol. 82, No. 1, 1990, pp. 4-6.

[14] M. I. Koukourakis, D. Papazoglou, A. GiatromaNolaki, G. Bougioukas, E. Maltezos and E. Sivridis, "VEGF Gene Sequence Variation Defines VEGF Gene Expression Status and Angiogenic Activity in Non-small Cell Lung Cancer," Lung Cancer, Vol. 46, No. 3, 2004, pp. 293-298.

[15] C. J. Watson, N. J. Webb, M. J. Bottomley and P. E. Brenchley, "Identification of Polymorphisms within the Vascular Endothelial Growth Factor (VEGF) Gene: Correlation with Variation in VEGF Protein Production," Cytokine, Vol. 12, No. 8, 2000, pp. 1232-1235.

[16] Q. Jin, K. Hemminki, K. Enquist, P. Lenner, E. Grzybowska, R. Klaes, R. Henriksson, B. Chen, J. Pamula, W. Pekala, H. Zientek, J. Rogozinska-Szczepka, B. Utracka-Hutka, G. Hallmans and A. Forsti, "Vascular Endothelial Growth Factor Polymorphisms in Relation to Breast Cancer Development and ProgNosis," Clinical Cancer Research, Vol. 11, No. 10, 2005, pp. 3647-3653.

[17] C. C. Lin, H. C. Wu, F. J. Tsai, H. Y. Chen and W. C. Chen, "Vascular Endothelial Growth Factor Gene-460 C/T Polymorphism is a Biomarker for Prostate Cancer," Urology, Vol. 62, No. 2, 2003, pp. 374-377.

[18] Y. S. Chae, J. G. Kim, S. K. Sohn, Y. Y. Cho, B. M. Ahn, J. H. Moon, S. W. Jeon, J. Y. Park, I. T. Lee, G. S. Choi and S. H. Jun, "Association of Vascular Endothelial Growth Factor Gene Polymorphisms with Susceptibility and Clinicopathologic Characteristics of Colorectal Cancer," Journal of Korean Medical Science, Vol. 23, No. 3, 2008, pp. 421-427.

[19] J. G. Kim, Y. S. Chae, S. K. Sohn, Y. Y. Cho, J. H. Moon, J. Y. Park, S. W. Jeon, I. T. Lee, G. S. Choi and S. H. Jun, "Vascular Endothelial Growth Factor Gene Polymorphisms Associated with ProgNosis for Patients with Colorectal Cancer," Clinical Cancer Research, Vol. 14, No. 1, 2008, pp. 62-66.

[20] I. H. Onen, E. Konac, M. Eroglu, C. Guneri, H. Biri and A. Ekmekci, "No Association Between Polymorphism in the Vascular Endothelial Growth Factor Gene at Position -460 and Sporadic Prostate Cancer in the Turkish Population," Molecular Biology Reports, Vol. 35, No. 1, 2008, pp. 17-22.

[21] M. Yamamori, M. Taniguchi, S. Maeda, T. Nakamura, N. Okamura, A. Kuwahara, K. Iwaki, T. Tamura, N. Aoyama, S. Markova, M. Kasuga, K. Okumura and T. Sa- 
kaeda, "VEGF T-1498C Polymorphism, a Predictive Marker of Differentiation of Colorectal AdeNocarciNomas in Japanese," International Journal of Medicial Science, Vol. 5, No. 2, 2008, pp. 80-86.

[22] T. F. Hansen, K. L. Spindler, K. A. Lorentzen, D. A. Olsen, R. F. Andersen, J. Lindebjerg, I. Brandslund and A. Jakobsen, "The Importance of $-460 \mathrm{C} / \mathrm{T}$ and $+405 \mathrm{G} / \mathrm{C}$ Single Nucleotide Polymorphisms to the Function of Vascular Endothelial Growth Factor A in Colorectal Cancer," Journal of Cancer Research and Clinical Oncology, Vol. 136, No. 5, 2010, pp. 751-758.

[23] P. Therasse, S. G. Arbuck, E. A. Eisenhauer, J. Wanders, R. S. Kaplan, L. Rubinstein, J. Verweij, M. Van Glabbeke, A. T. van Oosterom, M. C. Christian and S. G. Gwyther, "New Guidelines to Evaluate the Response to Treatment in Solid Tumors. European Organization for Research and Treatment of Cancer, National Cancer Institute of the United States, National Cancer Institute of Canada," Journal of the National Cancer Institute, Vol. 92, No. 3, 2000, pp. 205-216.

[24] M. Stephens, N. J. Smith and P. Donnelly, "A New Statistical Method for Haplotype Reconstruction from Population Data," American Journal of Human Genetics, Vol. 68, No. 4, 2001, pp. 978-989.

[25] H. Linardou, I. J. Dahabreh, D. Bafaloukos, P. Kosmidis and S. Murray, "Somatic EGFR mutations and efficacy of tyrosine kinase inhibitors in NSCLC," Nature Reviews Clinical Oncology, Vol. 6, No. 6, 2009, pp. 352-366.

[26] J. W. Neal and L. V. Sequist, "First-line Use of EGFR Tyrosine Kinase Inhibitors in Patients with NSCLC Containing EGFR Mutations," Clinical Advances in Hematology and Oncology, Vol. 8, No. 2, 2010, pp. 119-126.

[27] H. G. Kang, J. E. Choi, W. K. Lee, S. Kam, S. I. Cha, C. H. Kim, T. H. Jung and J. Y. Park, " $+61 \mathrm{~A}>$ G Polymorphism in the EGF Gene Does Not Increase the Risk of Lung Cancer," Respirology, Vol. 12, No. 6, 2007, pp. 902-905.

[28] C. H. Bosken, Q. Wei, C. I. Amos and M. R. Spitz, "An Analysis of DNA Repair as a Determinant of Survival in Patients with Non-small-cell Lung Cancer," Journal of the National Cancer Institute, Vol. 94, No. 14, 2002, pp. 1091-1099.

[29] L. Cheng, M. R. Spitz, W. K. Hong, and Q. Wei, "Reduced Expression Levels of Nucleotide Excision Repair Genes in Lung Cancer: A Case-control Analysis," CarciNogenesis, Vol. 21, No. 8, 2000, pp. 1527-1530.
[30] K. H. Lee, H. S. Min, S. W. Han, D. Y. Oh, S. H. Lee, D. W,Kim, S. A. Im, D. H. Chung, Y. T. Kim, T. Y. Kim, D. S. Heo, Y. J. Bang, S. W. Sung and J. H. Kim, "ERCC1 Expression by ImmuNohistochemistry and EGFR Mutations in Resected Non-small Cell Lung Cancer," Lung Cancer, Vol. 60, No. 3, 2008, pp. 401-407.

[31] D. Isla, C. Sarries, R. Rosell, G. Alonso, M. Domine, M. Taron, G. Lopez-Vivanco, C. Camps, M. Botia, L. Nunez, M. Sanchez-Ronco, J. J. Sanchez, Lopez-Brea, M. I. Barneto, A. Paredes, B. Medina, A. Artal and P. Lianes, "Single Nucleotide Polymorphisms and Outcome in Docetaxel-Cisplatin-Treated Advanced Non-Small-Cell Lung Cancer," Annual Oncology, Vol. 15, No. 8, 2004, pp. 1194-1203.

[32] A. Kalikaki, M. Kanaki, H. Vassalou, J. Souglakos, A. Voutsina, V. Georgoulias and D. Mavroudis, "DNA Repair Gene Polymorphisms Predict Favorable Clinical Outcome in Advanced Non-Small-Cell Lung Cancer," Clinical Lung Cancer, Vol. 10, No. 2, 2009, pp. 118-123.

[33] C. Camps, C. Sarries, B. Roig, J. J. Sanchez, C. Queralt, E. Sancho, N. Martinez, M. Taron and R. Rosell, "Assessment of Nucleotide Excision Repair XPD Polymorphisms in the Peripheral Blood of Gemcitabine/Cisplatin-treated Advanced Non-small-cell Lung Cancer Patients," Clinical Lung Cancer, Vol. 4, No. 4, 2003, pp. 237-241.

[34] The International HapMap Project, Nature, Vol. 426, No. 6968, 2003, pp. 789-796.

[35] R. Zhai, G. Liu, W. Zhou, L. Su, R. S. Heist, T. J. Lynch, J. C. Wain, K. Asomaning, X. Lin and D. C. Christiani, "Vascular Endothelial Growth Factor GeNotypes, Haplotypes, Gender, and the Risk of Non-Small Cell Lung Cancer," Clinical Cancer Research, Vol. 14, No. 2, 2008, pp. 612-617.

[36] R. S. Heist, R. Zhai, G. Liu, W. Zhou, X. Lin, L. Su, K., K. Asomaning, T. J. Lynch, J. C. Wain and D. C. Christiani, "VEGF Polymorphisms and Survival in Early-stage Non-Small-Cell Lung Cancer," Journal of Clinical Oncology, Vol. 26, No. 6, 2008, pp. 856-862.

[37] S. J. Lee, S. Y. Lee, H. S. Jeon, S. H. Park, J. S. Jang, G. Y. Lee, J. W. Son, C. H. Kim, W. K. Lee, S. Kam, R. W. Park, T. I. Park, Y. M. Kang, I. S. Kim, T. H. Jung and J. Y. Park, "Vascular Endothelial Growth Factor Gene Polymorphisms and Risk of Primary Lung Cancer," Cancer Epidemiology, Biomarkers \& Prevention, Vol. 14, No. 3, 2005, pp. 571-575. 